Family Profile No. 06, 2019

\title{
Median Age at First Marriage, 2017
}

\section{Author: Krista K. Payne}

The median age at first marriage in the United States has increased steadily since the mid-20th century. In the mid1950s, the median age was at a record low of just over 20 for women and 22 for men, but by 2018, the median age was almost 28 for women and nearing 30 for men (see Figure 1). This trend is partially due to a declining share of women ever married. In 2016, $31 \%$ of women aged 18 and older were never married compared to a low of $17 \%$ in 1960 (FP-18-17). The median age at first marriage has increased similarly for both men and women. Consequently, the gender gap in the median age at first marriage for men and women has persisted, fluctuating between 1.6 and 2.7 years. This profile uses data from the 2017 American Community Survey (ACS), 1-year estimates to track the trend in men's and women's median ages at first marriage. The ACS is ideal because it provides the best annual data on marital status and demographic characteristics allowing for direct estimation of the median age at first marriage (Simmons \& Dye, 2004). This is an update to our previous profiles on the topic for the years 2014 (FP-16-07), 2013 (FP-15-05), 2010 (FP-12-07), and 2008 (FP-09-03).

Figure 1. Median Age at First Marriage in the U.S., 1890-2018

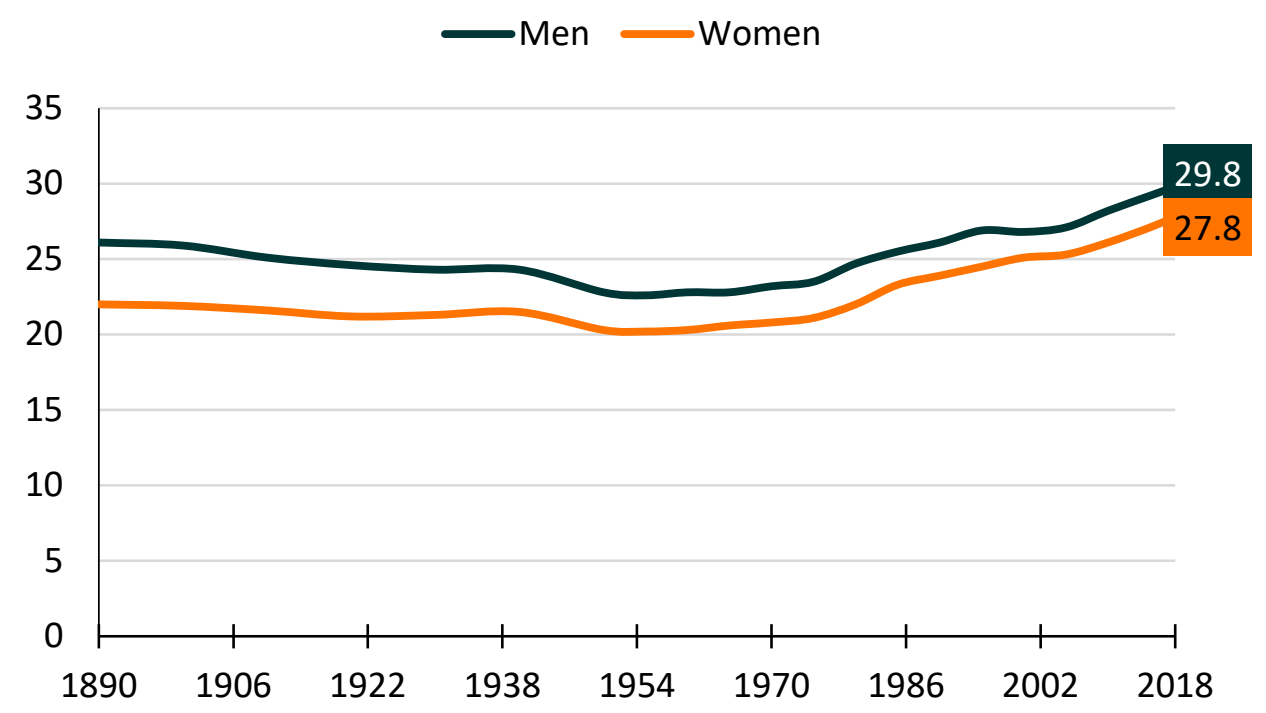

Source: NCFMR analyses of U.S. Census Bureau, Decennial Census, 1890-1940; U.S. Census Bureau, Current Population Survey, March and Annual Social and Economic Supplements, 1947-2018.

\section{References:}

Allred, C. A. (2018). Marriage: More than a century of change, 1900-2016. Family Profiles, FP-18-17. Bowling Green, OH: National Center for Family \& Marriage Research. https://doi.org/10.25035/ncfmr/fp-18-17

Anderson, L. \& Payne, K. K. (2016). Median age at first marriage, 2014. Family Profiles, FP-16-07. Bowling Green, OH: National Center for Family \& Marriage Research. https://www.bgsu.edu/ncfmr/resources/data/family-profiles/anderson-payne-median-age-firstmarriage-fp-16-07

Kawamura, S. (2009). Median age at first marriage in the U.S., 2008. Family Profiles, FP-09-03. Bowling Green, OH: National Center for Family \& Marriage Research. https://www.bgsu.edu/content/dam/BGSU/college-of-arts-and-sciences/NCFMR/documents/FP/FP-0903.pdf

Payne, K. K. (2015). Median age at first marriage, 2013. Family Profiles, FP-15-05. Bowling Green, OH: National Center for Family \& Marriage Research. https://www.bgsu.edu/ncfmr/resources/data/family-profiles/krista-k-payne-fp-15-05

Payne, K. K. (2012). Median age at first marriage, 2010. Family Profiles, FP-12-07. Bowling Green, OH: National Center for Family \& Marriage Research. https://www.bgsu.edu/content/dam/BGSU/college-of-arts-and-sciences/NCFMR/documents/FP/FP-12-07.pdf 


\section{Median Age at First Marriage by Race and Ethnicity}

- Black men and women have the highest median ages at first marriage, at 32.0 for men and 30.4 for women.

- Among men, Whites have the lowest median ages at first marriage, 29.4. Among women, Hispanics have the lowest median age at first marriage, 27.5.

- Hispanic men and women have the largest gender gap, at 2.3 years. Among the other racial/ethnic groups examined, the gap is around 1.5 years.
Figure 2. Median Age at First Marriage by Race and Ethnicity, 2017

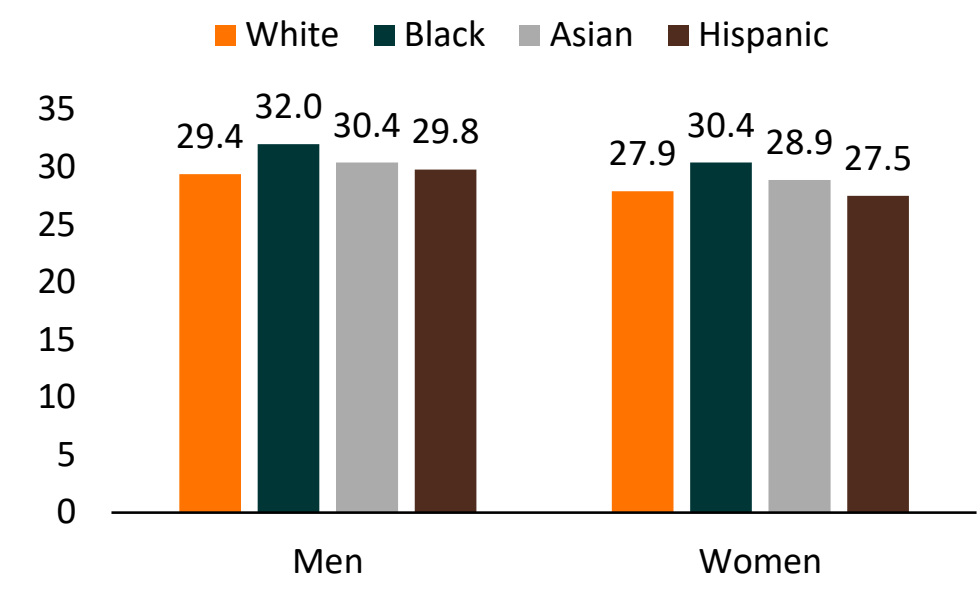

Source: NCFMR analyses of U.S. Census Bureau, American Community Survey, 1-yr est

\section{Median Age at First Marriage by Educational Attainment}

Figure 3. Median Age at First Marriage by Educational Attainment, 2017

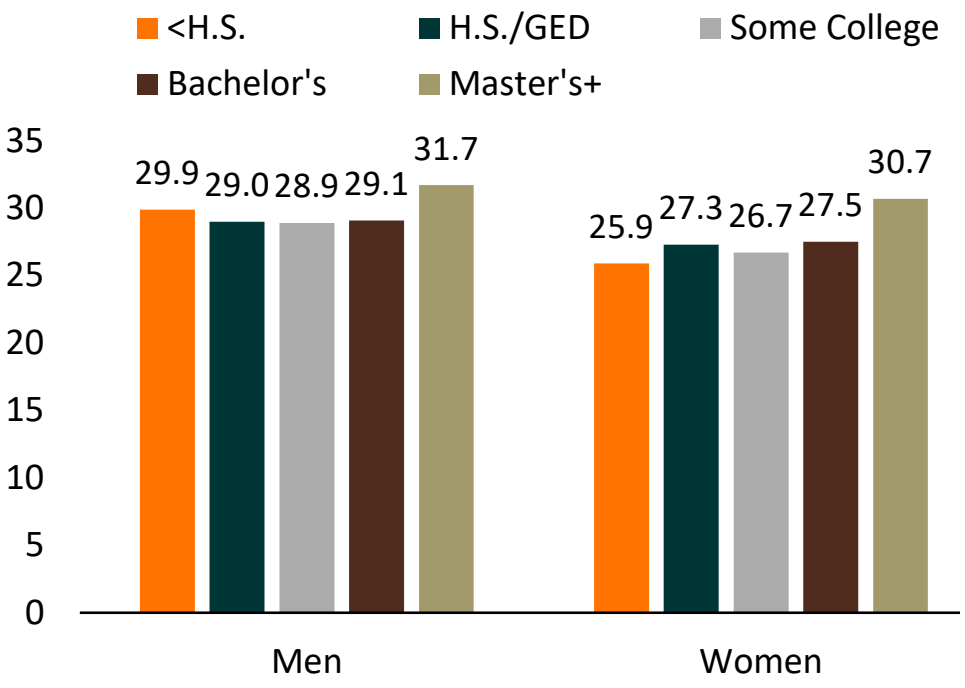

Source: NCFMR analyses of U.S. Census Bureau, American Community Survey, 1-yr est.
- Among men who married last year, the relationship between educational attainment and age at first marriage is u-shaped. Men with less than a high school education and men with at least a master's degree had the two highest ages at first marriage at 30 and 32, respectively. All other men were 29 years old when they first married.

- Women show a different pattern - their median age at first marriage increased as their educational attainment increased. Those with less than a high school education had the lowest age at first marriage at 26 , and women with at least a master's married around age 31 . The remaining women married at about age 27 .

- The largest gender gap is between men and women with less than a high school education at four years, whereas those with at least a master's degree had the smallest of only one year.

\section{Suggested Citation:}

Payne, K. K. (2019). Median age at first marriage, 2017. Family Profiles, FP-19-06. Bowling Green, OH: National Center for Family \& Marriage Research. https://doi.org/10.25035/ncfmr/fp-19-06. 